Ophthalmologica 1980;180(Suppl 1):I-IIII

\title{
Contents, Vol. 180, Supplementary, 1980
}

\section{Preface V}

Preamble VI

Introduction

Therapeutic Possibilities of Using an Oxygen-Metabolism Activator (Solcoseryl ${ }^{\circledR}$ ) by theSystemic and Topical Route in Ophthalmology 1

Chapter I

Research on the Eyes of X-Ray-Irradiated Mice with and without PharmacologicalProtection 3

Chapter $\prod$

Research on the Possible Topical Use of a New Drug (Solcoseryl Eye-Gel) in the Treatment of Corneal Affections 18

Chapter HI

Research on the Corneas of Rabbits after the Application of Hard and HydrophilicContact

Lenses for Various Periods of Time with and without Pharmacological Protection with

Solcoseryl 26

Chapter IV

Research on the Ciliary Processes in Rabbits Subjected to Experimental Intoxicationwith Sodium Benzoate and Sodium lodate with and without Pharmacological Protectionwith Solcoseryl

35

Chapter V

Study of the Retinas of Rabbits Subjected to Experimental Intoxication with Sodium Benzoate and Sodium lodate with and without Pharmacological Protection with Solceseryl 43 C. Chapter $\mathrm{V}$

Study of the Retinas of Rabbits Subjected to Experimental Intoxication with Sodium Benzoate and Sodium lodate with and without Pharmacological Protection with Solceseryl 43 